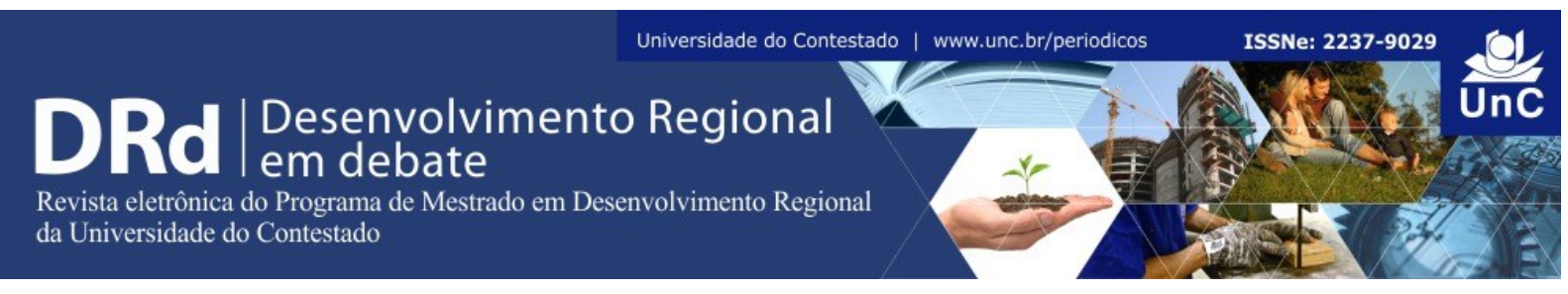

\title{
O DESEMPENHO DAS REGIÕES ECONÔMICAS DO TOCANTINS EM TEMPOS DE CRISE (2010-2015): UMA ANÁLISE ESPACIAL
}

\author{
Thiago José Arruda de Oliveira ${ }^{1}$ \\ Waldecy Rodrigues ${ }^{2}$
}

\begin{abstract}
RESUMO
O principal objetivo deste artigo consistiu em analisar a relação entre interações espaciais e crises nas Regiões Econômicas do Tocantins (TO). Por dependerem dos recursos oriundos da União e também pelos serviços ofertados nos polos nacionais, Brasília e São Paulo, qualquer perturbação advinda desses lugares afeta negativamente as suas bases produtivas. Mensurou-se esse fenômeno por meio do I de Moran Global e Local (LISA) em dois períodos (2010/2012 e 2013/2015). Os resultados apontaram que as relações espaciais entre as Regiões Econômicas do Tocantins foram impactadas pelas crises de diferentes formas, sendo que no norte do estado houve uma maior retração de suas atividades produtivas. $\mathrm{Na}$ faixa central, onde localiza a capital, Palmas, ocorreu recuperação em vista da aproximação entre as principais centralidades urbanas do estado. Nesse sentido, afirmou-se que esse cenário aconteceu diante das diferenças de conhecimentos produtivos entre as regiões do Tocantins. Sendo assim, ressaltou-se a importância de se analisar as aglomerações urbanas como forma de superar crises.
\end{abstract}

Palavras-chave: Interações Espaciais. Economia Regional. Crises.

\section{THE ECONOMICS REGIONS PERFORMANCE OF TOCANTINS DURING THE YEARS OF CRISIS (2010/2015): A SPATIAL ANALYSIS}

\begin{abstract}
This paper analyzed the relation between spatial interactions and crisis in the region's economics of Tocantins (TO). Due to its extreme dependence on national poles, Brasília e São Paulo, and resources provided by the federal government, any external disturbance could seriously unbalance such economic bases. To measure it, the spatial indexes Moran's I (global and local) in two periods (2010/2012 and 2013/2015). Our findings illustrate that the process of dynamic spatial networks in the Tocantins is directly affected by instabilities in different contexts, mainly in the north of the state, the most region prejudiced for the crisis. In the central, where localized the capital, Palmas, overcame the crisis owing to the agglomeration of aim urban centralities. This scenario happened because of the differences in the accumulation of
\end{abstract}

\footnotetext{
${ }^{1}$ Doutor em Desenvolvimento Regional e Agronegócio (UNIOESTE). Bolsista nível pós-doutorado do Programa de Pós-Graduação em Desenvolvimento Regional da Universidade Federal do Tocantins (UFT), Palmas, Tocantins, Brasil. E-mail: thiago.arruda85@gmail.com. ORCID: https://orcid.org/0000-0002-7090-0202 ${ }^{2}$ Doutor em Ciências Sociais (UnB). Professor associado do curso de graduação em Ciências Econômicas e do Programa de Pós-Graduação em Desenvolvimento Regional da Universidade Federal do Tocantins (UFT), Palmas, Tocantins, Brasil. E-mail: waldecy@terra.com.br. ORCID: https://orcid.org/0000-0002-5584-6586
}

DRd - Desenvolvimento Regional em debate (ISSNe 2237-9029) 
skills in the Tocantins. Therefore, it is important to emphasize that urban agglomerations overcome crises.

Keywords: Spatial Interactions. Regional Economics. Crises.

\section{INTRODUÇÃO}

A análise sobre as interações espaciais entre as regiões ao longo do tempo advém da Teoria do Lugar Central de Walter Christaller (1893-1969). A partir disso, tem-se a definição de região polarizada, conceitualizado por Perroux (1977), e de região econômica, noção formulado por Jacques Boudeville (1919-1975). Desse modo, o crescimento regional depende do nível de demanda por comércio e serviços urbanos especializados (conhecimento produtivo) sobre a área atendida pela centralidade urbana (NORTH, 1977).

No caso do Tocantins (TO), as diferenças de funcionalidade dos seus núcleos resultaram em desigualdades espaciais. Enquanto que os polos de Palmas, Paraíso do TO e Porto Nacional, situados na faixa central, realizam entre eles volumosas trocas comerciais e trânsito de pessoas (OLIVEIRA; PIFFER, 2015), a incidência desse fenômeno com a mesma intensidade em outras partes do estado é limitado. Como resultado, a incapacidade das suas regiões periféricas em dinamizar as relações espaciais acentuaram a sua dependência pelos repasses da União (BECKER, 2005), situação que os tornam vulneráveis diante das crises pela qual o Brasil atravessou nos últimos anos. Além disso, as únicas economias regionais que superaram as instabilidades foram aquelas que acumularam conhecimentos produtivos ao longo do tempo, situação que viabilizou a criação de empreendimentos em tempos de crises recentes (BISHOP, 2019).

Em vista de tais observações, analisou-se o desempenho das economias regionais no Tocantins em dois períodos turbulentos: 2010/2012 (crise externa) e 2013/2015 (crise interna). A escolha desse ente federativo relaciona-se com o aumento da importância dos seus principais polos: Araguaína e Palmas, no contexto regional (OLIVEIRA; PIFFER, 2017a). Outrossim, evidências apontam que as instabilidades impactam de diferentes modos nas regiões, sendo que algumas recuperaram-se da tensão em pouco tempo, outras, porém, continuaram com queda na sua produção (ESPINAL，2010; ERIKSON; HANE-WEIJMAN, 2015; PONTAROLO; SERPIERI, 2018).

Para tanto, utilizou-se do indicador de associação espacial I de Moran Global e Local (LISA) como forma de mensurar o nível de interação entre as economias regionais tocantinenses. O subíndice FIRJAN de Desenvolvimento Municipal Emprego \& Renda e a quantidade de postos de trabalhos foram as principais variáveis empregadas na análise. Além dessa introdução, discorreu-se sobre as modificações no espaço tocantinense ao longo dos séculos, e em seguida, sobre o período turbulento na qual o País atravessou nesta década. Posteriormente, apresentou-se os procedimentos metodológicos e debateu-se sobre os resultados da pesquisa. Enfim, concluiu-se o trabalho à luz do referencial teórico e bibliográfico. 


\section{A EVOLUÇÃO ESPACIAL NO ESTADO DO TOCANTINS}

No Tocantins, como parte integrante do Brasil-Colônia, a criação de gado em estado em modo semisselvagem (PRADO JÚNIOR, 2012) e o aprisionamento de índios eram as suas primeiras atividades. Na medida em que essas forças adentravam nos territórios indígenas, descobriram-se áreas auríferas, dentre essas, destacou-se algumas que se localizam atualmente no sudeste tocantinense. Embora tenha uma importância considerável em seu processo de ocupação, a mineração obteve um ciclo curto de duração, haja visto que nenhuma parte das riquezas geradas se reinvestiu em novas capacidades produtivas, tampouco na manutenção das bases existentes (OLIVEIRA; PIFFER, 2017a).

O problema é que diferente da América Espanhola, onde o ouro situava-se em morros e montanhas, o dos portugueses encontrava-se nos barrancos dos corpos d'águas. A intensa retirada do metal nas encostas logo esgotava as minas, resultando no completo abandono dessas áreas (SALLES, 1992). Neste sentido, sem opções de realizar trocas comerciais contínuas, o norte goiano/Tocantins sobrevivia, mesmo após o término do período colonial, por meio de produções com limitada importância no contexto nacional. Os rios, as principais vias de escoamento da produção e de contato com as outras regiões, contribuíram para a consolidação desse cenário, dado que a viagem se transformava numa completa aventura (FLORES, 2009).

Sob essa perspectiva, surgiram poucos núcleos dignos de se configurarem como uma centralidade regional. Entre esses, destacou-se Porto Nacional (Porto Real/Imperial), Tocantinópolis (Bela Vista) e Pedro Afonso, todos localizados nas margens do rio Tocantins. No restante do futuro estado, o isolamento, resultado da ausência de interações espaciais, consolidou o espraiamento demográfico e a irrelevância do seu mercado consumidor. Por isso, até meados do século XX, inexistia na bacia Araguaia-Tocantins regiões com modernas bases econômicas espacialmente interligadas com os seus centros de produção (Figura 1). 
Figura 1 - Localização geográfica dos principais centros urbanos da bacia Araguaia-Tocantins até meados do século XX.

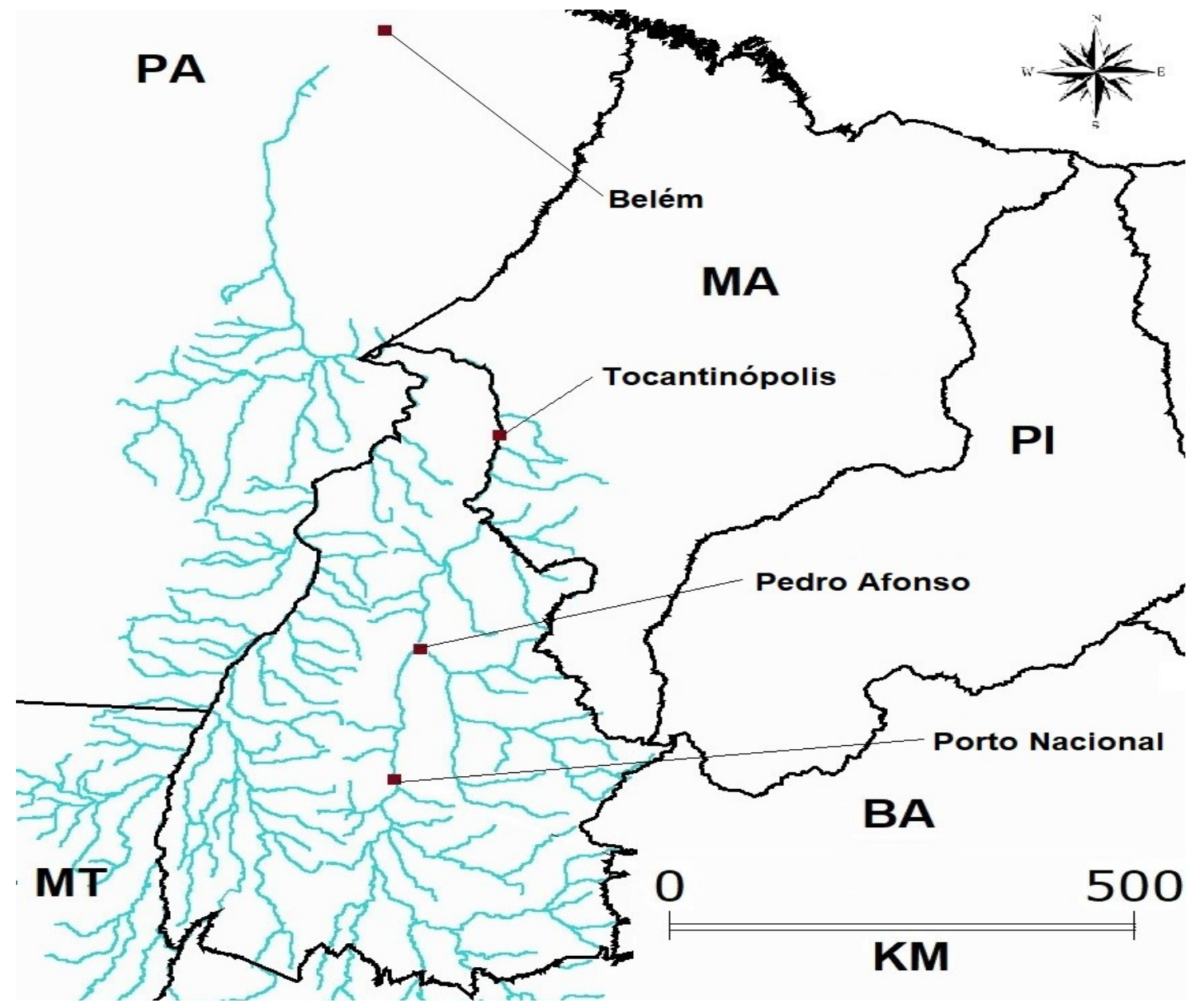

Fonte: Oliveira; Piffer (2017a). Adaptado pelos autores.

A principal praça comercial da bacia Araguaia-Tocantins, Belém, estado do Pará, encontrava-se distante de Tocantinópolis, Pedro Afonso e Porto Nacional (Figura 1), além do mais, o trajeto era penoso diante dos obstáculos presentes ao longo dos rios. Desse modo, a integração entre as partes envolvidas ocorria de forma sazonal, situação que restringe os efeitos de encadeamento nas economias regionais (HIRSCHMAN, 1977). As alterações espaciais aconteceram somente a partir de 1930, quando o Estado interferiu diretamente nas regiões interioranas brasileiras.

Como resultado das políticas de ocupação territorial, surgiram as cidades de Goiânia e Brasília, que com o passar do tempo adquiriram características de um polo regional ao concentrar centros comerciais e serviços inexistentes em outras partes do Cerrado. Ademais, a instalação de escritórios do Instituto Nacional de Colonização e Reforma Agrária (INCRA), a disponibilidade de linhas de crédito do Banco do Brasil e a criação da Empresa Brasileira de Pesquisa Agropecuária (EMBRAPA) promoveram a entrada das frentes agrícolas. Essas ações transformaram a estrutura econômica espacial do então norte goiano/Tocantins (Figura 2). 
Figura 2 - Localização geográfica das microrregiões e dos polos sub-regionais tocantinenses e as suas principais vias de ligação com o Distrito Federal e Goiânia.

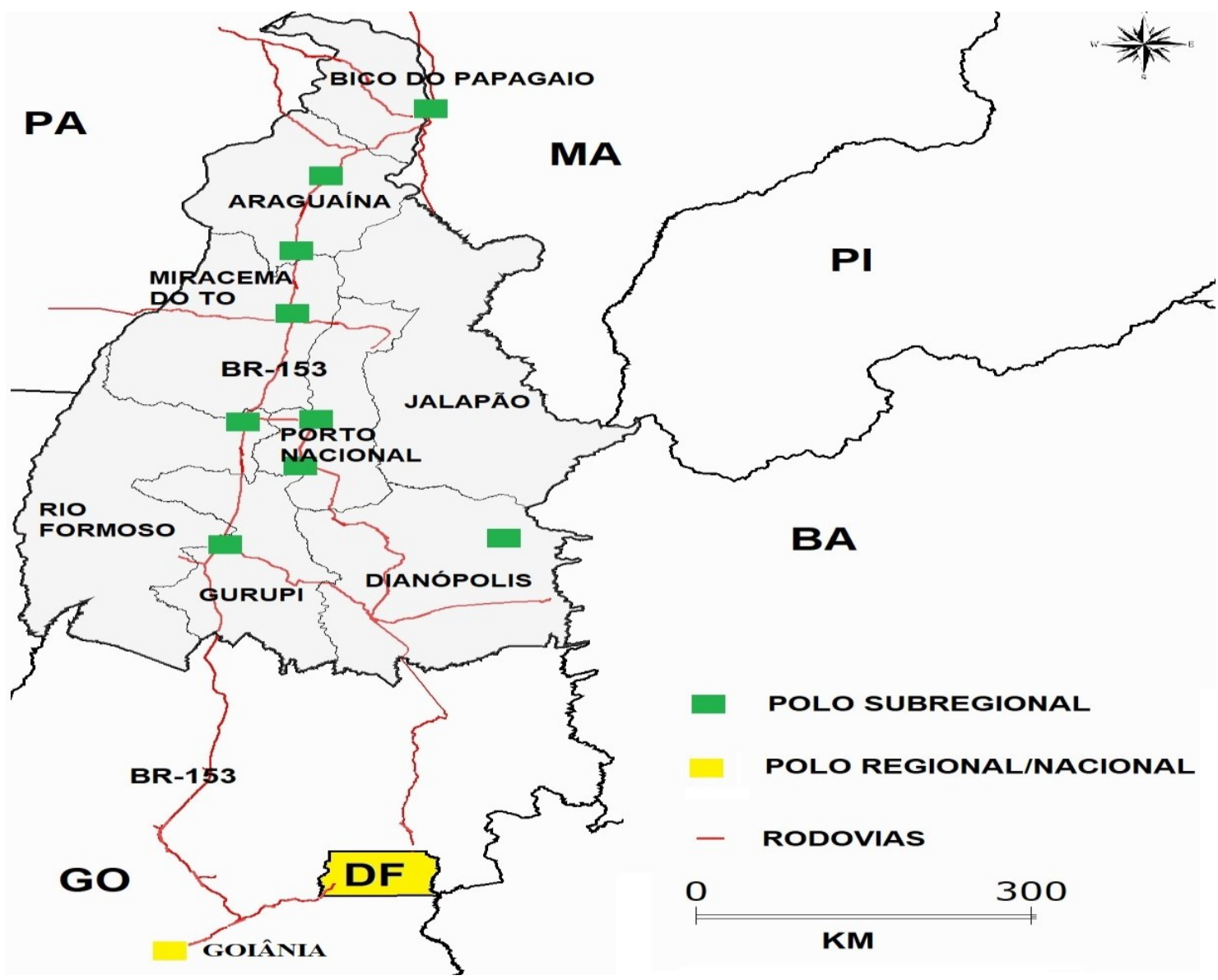

Fonte: Oliveira; Piffer (2017a). Adaptado pelos autores.

A BR-153, possibilitou o deslocamento ágil entre os polos sub-regionais localizados ao longo desse trajeto terrestre até o Distrito Federal e Goiânia (Figura 2). De fato, somente a partir da efetivação desses dois pontos no Planalto Central brasileiro se iniciou o processo de deslocamento da dinâmica espacial dos rios para as rodovias federais. Esse acontecimento, no primeiro momento, incentivado pelo Estado, tinha como principal objetivo a ocupação agrícola (BECKER, 2005).

Por outro lado, nem todas as microrregiões tocantinenses se beneficiaram de tamanha transformação. A de Dianópolis, distante das principais rodovias, (Figura 2) assim como o Jalapão, que tampouco possui um centro polarizador, marginalizaram-se no contexto produtivo. Amenizou-se a situação na medida em que a nova capital estadual, Palmas, expandiu o seu raio de atuação, e os agricultores provenientes do Sul e Sudeste brasileiro apropriaram-se das terras com o intuito de implementar a cultura mecanizadas (OLIVEIRA; PIFFER, 2017a). Assim, iniciou-se o processo de difusão das novas bases econômicas em todo o antigo norte de Goiás.

Diante disso, a partir de 2000, todas as microrregiões do Tocantins inseriram em alguma área de mercado promovidos pelos polos nacionais ou regionais. Embora Belém arrefeceu o seu nível de atuação na Amazônia oriental, ainda exerce poder central no Bico do Papagaio e Araguaína. Nas demais, Goiânia-GO e Brasília-DF detêm poderio absoluto ao atrair imigrantes tocantinenses através do comércio, serviços e ofertas de empregos (BRASIL, 2008). 
Recentemente, estudos como o de Oliveira; Piffer (2017a) e Oliveira; Rodrigues (2018) demonstraram que todas as regiões do Tocantins possuem atividades produtivas em destaque e núcleo urbanos que polarizaram uma parte do estado. Nesse contexto, a agropecuária, a administração pública e o comércio/serviços são a base das suas economias. As indústrias, por outro lado, ainda têm uma representatividade bastante limitada na pauta estadual.

Em vista deste cenário, o elemento urbano, estruturada a partir das trocas comerciais promovidos pelos seus setores produtivos, adquiriu uma vital importância na evolução do espaço tocantinense. Esse adensamento de capital humano e financeiro em pontos específicos permitiu que os residentes satisfizessem as suas necessidades sem percorrer consideráveis distâncias sob um sistema de transporte deficitário. Desse modo, o Instituto Brasileiro de Geografia e Estatística (IBGE) no ano de 2017, atualizou a sua malha regional ao substituir o conceito de microrregião para Região Geográfica Imediata (RGI) no sentido de corresponder a essa situação. No Tocantins, são oito RGIs e três Regiões Geográficas Intermediárias (RGINT): Araguaína, Gurupi e Palmas (Figura 3).

Figura 3 - Localização geográfica das Regiões Geográficas Imediatas (RGIs) Intermediárias (RGINTs) com os seus respectivos polos.

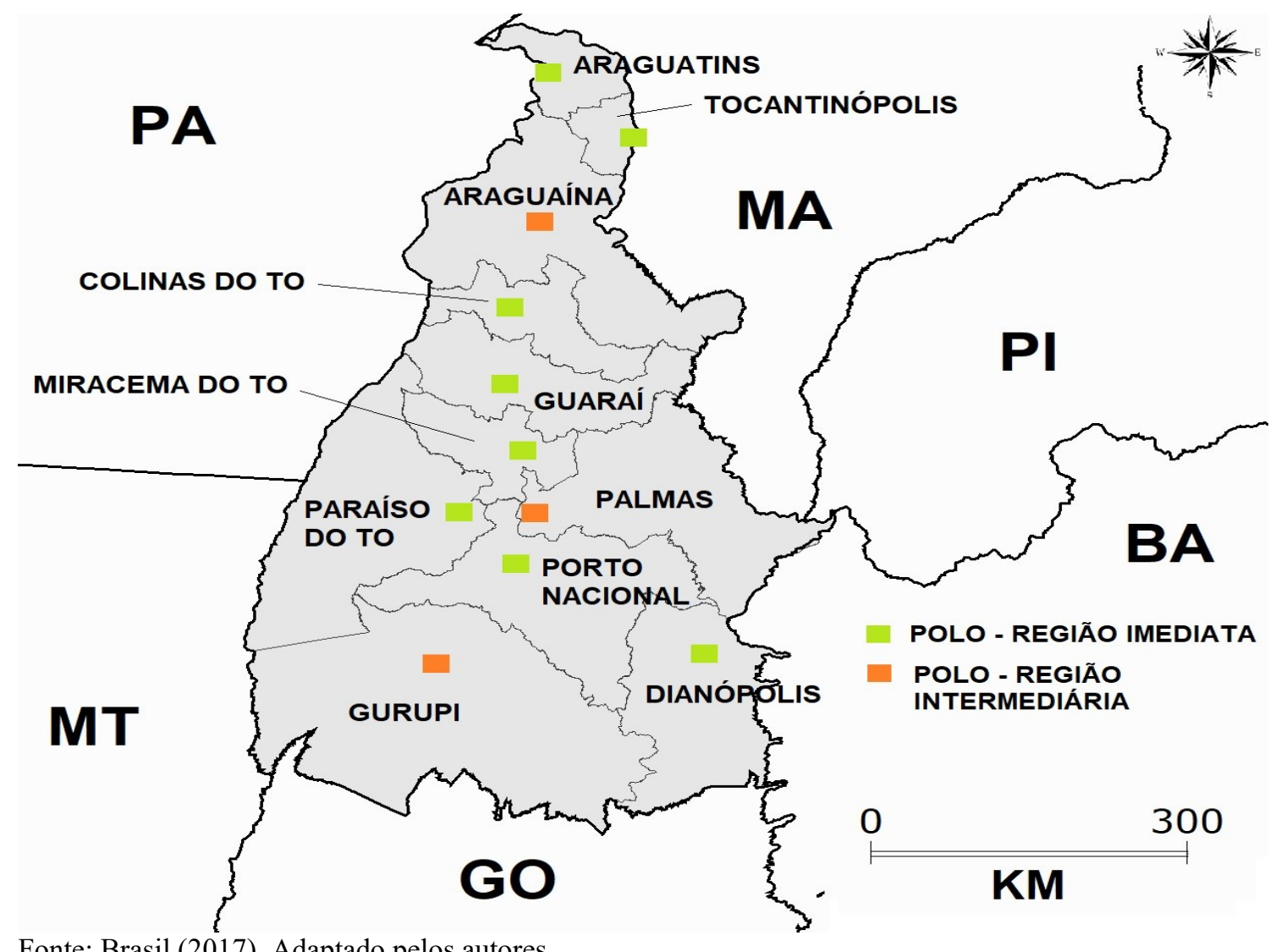

Fonte: Brasil (2017). Adaptado pelos autores.

Os polos regionais tocantinenses se encontram próximos entre si (Figura3), configuração distinta da observada nos séculos anteriores. As capitais Belém-PA, Brasília-DF e Goiânia-GO continuaram como os principais agentes polarizadores desta parte do País, porém dividem essa responsabilidade com Araguaína-TO, Gurupi-TO e Palmas-TO. Por sua vez, essas três, ao concentrarem comércio e serviços especializados, hierarquizaram o espaço urbano estadual conectando as demais regiões do Tocantins com o Brasil e o mundo. 


\section{AS CRISES DO SÉCULO XXI}

As crises econômicas estão geralmente vinculadas a problemas de desordem financeira. No ocorrido em 1997, iniciou-se no leste asiático e se difundiu para a Rússia e América Latina, e como consequência, o mundo mergulhou no pior apuro econômico desde a Grande Depressão de 1929 (GILPIN, 2000). Dez anos após os distúrbios na Ásia, o sistema financeiro mundial entrou novamente na adversidade, desta vez iniciando-se na liderança mundial: os Estados Unidos da América.

No caso americano, encetou-se precisamente no final de 2008, fazendo com que o ritmo de crescimento econômico mundial diminuísse drasticamente. O motivo deveu-se à queda das importações por parte das suas famílias, que perderam o seu poder de consumo devido à falência do setor imobiliário (HERSEN; LIMA, 2010). Essa desaceleração afetou o desempenho produtivo brasileiro no período seguinte, 2010/2013 (Figura 4).

Figura 4 - Variação anual (\%) do Produto Interno Bruto nacional (PIB) à preços de mercado com deflator implícito - 2009/2016.

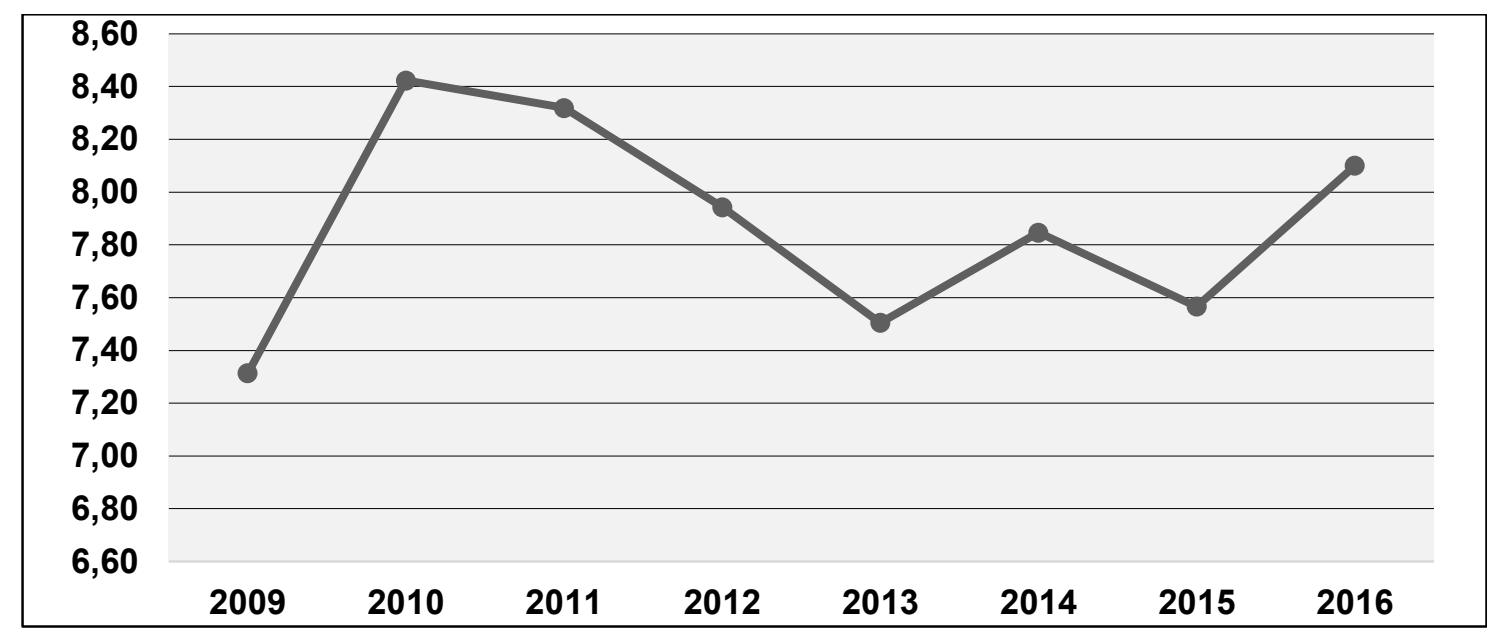

Fonte: Instituto de Pesquisa Econômica Aplicada (IPEA). Elaborado pelos autores.

Embora a crise imobiliária tenha arrefecido o desempenho econômico do País, situação que acarretou na recessão industrial, demissões, principalmente dos empregados pertencente às classes D e E, e o aumento da pobreza nas regiões metropolitanas, o governo agiu para minimizar as incertezas em curto prazo. Para tanto, desonerou o Imposto sobre Produtos Industrializados (IPI) nos produtos da "linha branca", veículos automotores e móveis, criação do programa "Minha Casa, Minha Vida" e a expansão do crédito disponibilizado pelo Banco Nacional de Desenvolvimento Econômico e Social (BNDES).

Além disso, o setor terciário absorveu a massa de trabalhadores ociosos e o comércio internacional de produtos nacionais primários e semimanufaturados, a maior parte destinada à China e nações árabes, asseguraram o superávit primário. Em consequência disso, a economia brasileira recuperou-se em curto prazo da queda originada no exterior entre o período de 2010 e 2011. A nota destoante foi a manutenção da taxa de juros elevada, contrastando com a política fiscal anticíclica e a creditícia dos bancos públicos (PAULA; PIRES, 2017). 
Nos anos seguintes, o governo continuou com a política de expansão dos gastos públicos para compensar a limitada efetividade na redução da taxa Selic e da desvalorização cambial. Esses fatores prejudicaram o desempenho do PIB entre os anos de 2014 e 2015, desacelerandoo em um período também marcado pela crise hídrica e na retração do poder de consumo das famílias brasileiras. Sem opções, o Palácio do Planalto revisou a meta físcal em um montante que se mostrou insuficiente para acomodar a queda adicional de receitas.

Em vista das adversidades apresentadas, aumentou-se a insatisfação popular, tendo como frente a consolidada e heterogênea classe média brasileira, que já protestavam desde o início e durante a Copa das Confederações, em 2013, evento antecessor do mundial de futebol. Embora as primeiras manifestações estivessem sob o comando de universitários e apartidários, almejando, inicialmente, a diminuição do preço da passagem de ônibus, nos anos seguintes transformaram-se em verdadeiras incitações ideológicas e partidárias. A mudança de postura relacionou-se com a entrada da grande mídia, encabeçada pela Rede Globo, que disseminou informações em prol dos ideais conservadores e protofascistas (SOUZA, 2017).

Sem apoio do Congresso Nacional, da intitulada "nova classe média" e dos veículos de comunicação, além de enfrentar a desaceleração da economia, a presidente Dilma Rousseff, após um longo processo, sucumbiu ao impeachment em agosto de 2016. Com isso, finalizou-se um período de 12 anos do Partido dos Trabalhadores no comando do Palácio do Planalto. Assume-se o vice-presidente, Michel Temer, do Movimento Democrático Brasileiro, prometendo a estabilidade política e do crescimento do Produto Interno Bruto brasileiro, que se encontrava em recessão (PAULA; PIRES, 2017).

O Tocantins, por sua vez, incorpora-se no rol de Unidades da Federação que dependem excessivamente dos repasses da União, sentindo, também, os efeitos das crises. Agravou-se a situação diante do seu restrito mercado consumidor e do seu limitado estoque de conhecimentos produtivos (OLIVEIRA; RODRIGUES, 2018). Desse modo, variações negativas nas transferências orçamentárias advindas de Brasília comprometeram o seu desempenho produtivo (Figura 5).

Figura 5 - Taxa de crescimento real (IPCA) do Fundo de Participação dos Estados (FPE) no Tocantins e do seu Produto Interno Bruto - 2009/2015 (ano base = anterior).

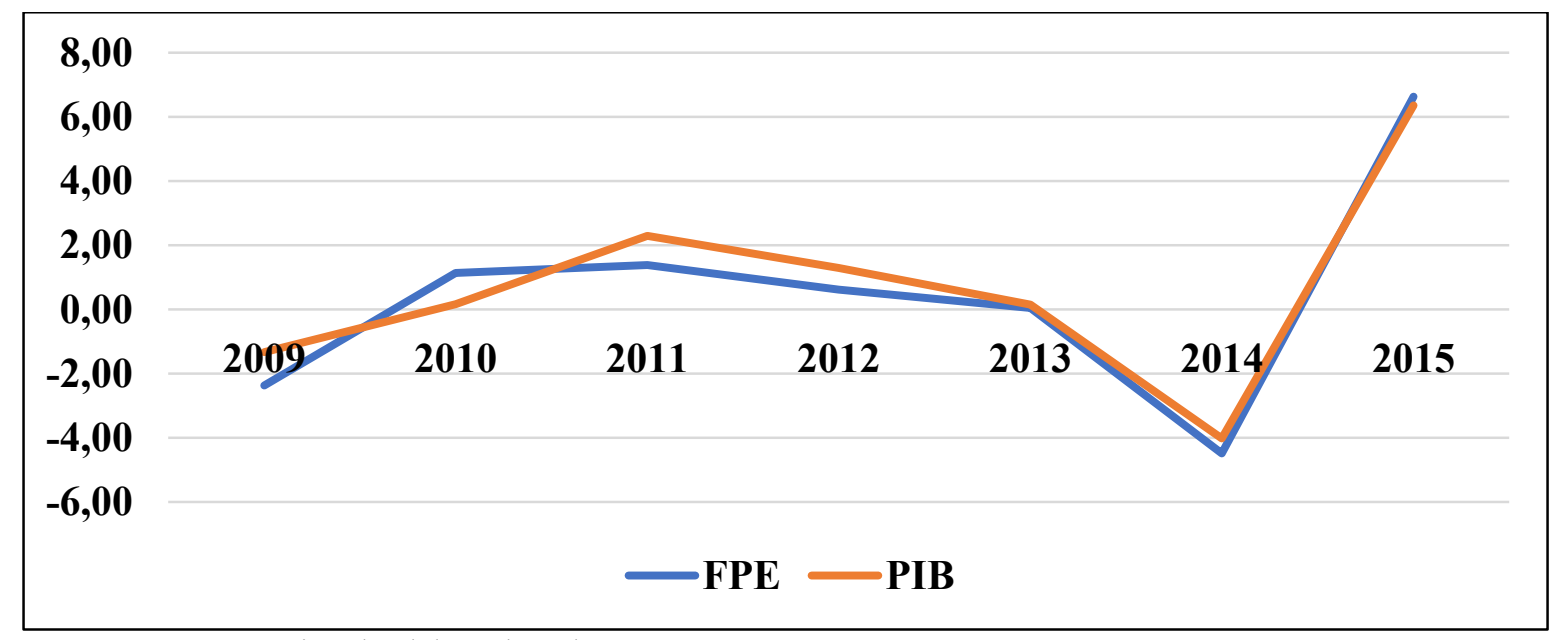

Fonte: Tesouro Nacional. Elaborado pelos autores.

DRd - Desenvolvimento Regional em debate (ISSNe 2237-9029) 
Houve uma retração no repasse do Fundo de Participação dos Estados para o Tocantins entre 2011 e 2014 (Figura 5). Coincidentemente, é o período em que ocorreram os choques internos que prejudicaram a produção nacional, e, por conseguinte, a economia tocantinense. Embora denotou-se um crescimento do repasse a partir de 2015, foi insuficiente para cobrir a perda nos anos anteriores.

Resumidamente, observou-se que no período de 2010 a 2012 a produção nacional se recuperou brevemente da crise iniciada nos Estados Unidos (2008-2009). Contudo, entre 2013 e 2015, ínterim caracterizado pela acentuada queda no PIB nacional e no repasse do FPE para os estados, ocorreu uma das maiores recessões da história brasileira. Ante o exposto, tais acontecimentos foram divididos da seguinte forma (Quadro 1).

Quadro 1 - Características das crises entre 2010 e 2015.

\begin{tabular}{|c|l|l|}
\hline Período & \multicolumn{1}{|c|}{ Origem } & Comportamento da economia brasileira \\
\hline $2010-2012$ & $\begin{array}{l}\text { Crise mundial (epicentro no sistema financeiro- } \\
\text { imobiliário dos Estados Unidos) }\end{array}$ & Recuperação no curto prazo \\
\hline $2013-2015$ & $\begin{array}{l}\text { Choques internos (ajustes econômicos, instabilidade } \\
\text { política e desabastecimento hídrico) }\end{array}$ & Desaceleração e recessão \\
\hline
\end{tabular}

Fonte: Paula e Pires (2017). Elaborado pelos autores.

Em vista disso, têm-se períodos distintos na economia brasileira durante a segunda década do século XXI, sendo que o primeiro (2010/2012) se trata de uma fase onde houve uma certa recuperação. Em compensação, a de 2013-2015 possui como característica marcante a forte retração produtiva no País ocasionada pelos choques internos. Isto prejudicou o desempenho das suas Unidades da Federação, especialmente o Tocantins, que depende excessivamente dos repasses da União em vista da sua limitada capacidade produtiva. $\mathrm{O}$ próximo passo consiste em analisar se essas retrações comprometeram as relações espaciais entre as regiões tocantinenses.

\section{MATERIAL E MÉTODOS}

O IBGE, no ano de 2017, atualizou a sua malha regional ao substituir o conceito de microrregião para Região Geográfica Imediata -RGI-. No Tocantins, são oito RGIs e três Regiões Geográficas Intermediárias -RGINT-, Araguaína, Palmas e Gurupi, equivalente à concepção de macrorregião (Figura 6). Neste sentido, entendeu-se que essas formulações, ao utilizarem como base teórica o conceito de polos e centralidades urbanas, configuram-se em Regiões Econômicas. Com isso, possibilitou-se uma análise comparando os seus desempenhos ao longo do tempo. 
Figura 6 - As Regiões Geográficas Imediatas e Intermediárias no Tocantins.

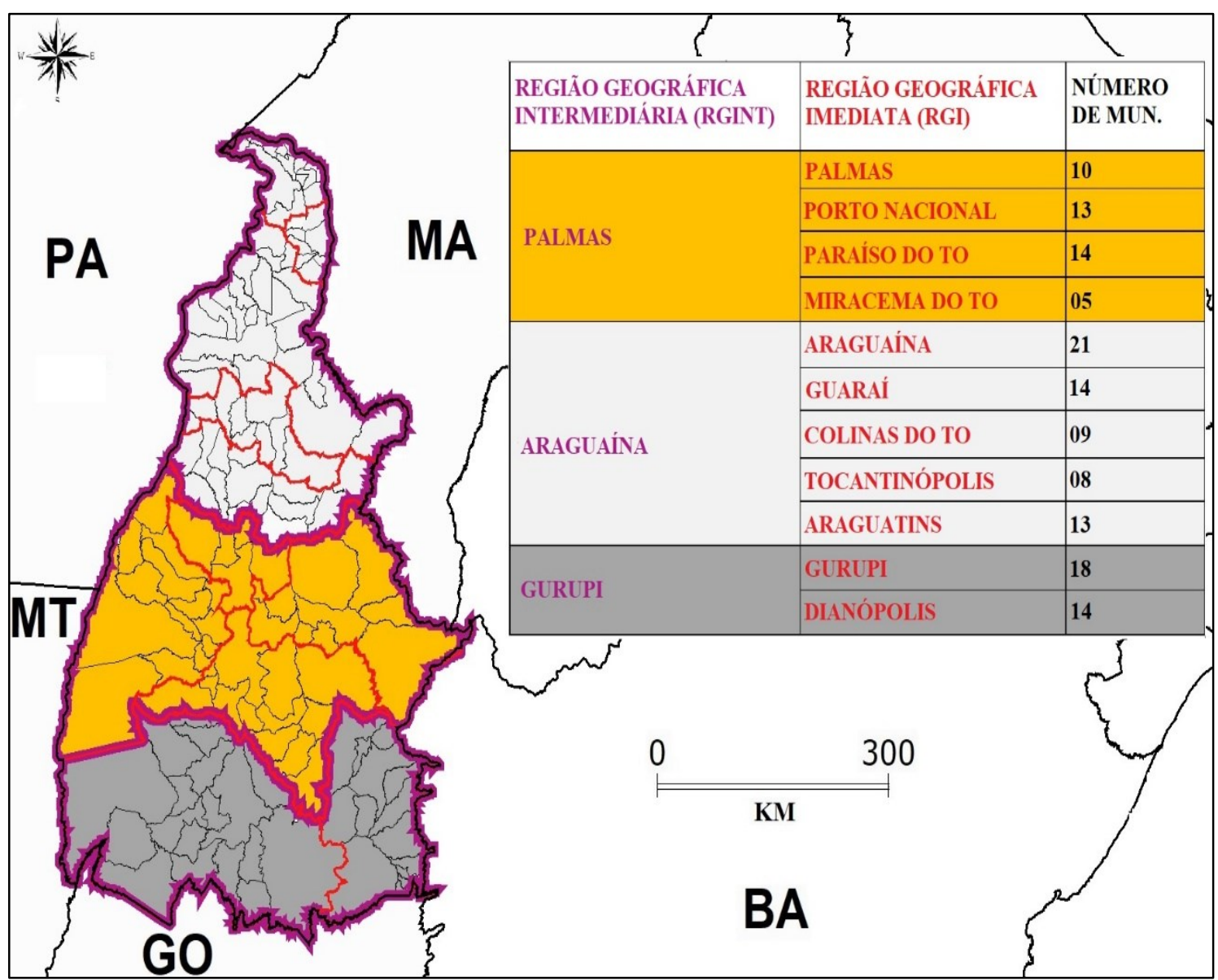

Fonte: Brasil (2017).

A Região Geográfica Imediata de Araguaína é a RGIn com maior quantidade de municípios (Figura 6). No outro extremo, Miracema do Tocantins tem apenas cinco, concluindo-se que as áreas econômicas tocantinenses possuem diferentes configurações espaciais. Embora transpareça que as variações no que concerne ao tamanho dos recortes prejudiquem a análise, essa diversificação estrutural explica as múltiplas manifestações geradas nas economias regionais, uma vez que todas estão espacialmente conectadas de algum modo.

O próximo passo consistiu em selecionar as variáveis que demonstram o nível de conhecimento produtivo nas Regiões Econômicas do TO ao longo dos anos de crise. Espinal (2010) utilizou-se do Produto Interno Bruto em sua análise, porém esse é um parâmetro sujeito à crítica enfatizada por Souza; Spinola (2017), que relatam a inadequação desse instrumento em mensurar o nível de desenvolvimento das regiões ou de qualquer país em múltiplas dimensões. Ademais, o aumento da produção nem sempre configura em melhorias na qualidade de vida e no bem-estar comum.

Diante disto, optou-se pelo subíndice Emprego \& Renda advindo do Índice FIRJAN de Desenvolvimento Municipal (IFDM). Essa escolha amparou-se na pesquisa de Oliveira; Piffer (2017b), que o utilizou para identificar as regiões do Centro Norte brasileiro cujas bases institucionais modificaram os seus desempenhos entre 2000 e 2013. Se o indicador alcançar um valor acima de 0.8 , significa que a área de estudo atingiu alto estágio de desenvolvimento (Quadro 2). 
Quadro 2 - Composição do IFDM Emprego \& Renda e a sua classificação

\begin{tabular}{|l|l|}
\hline \multicolumn{1}{|c|}{ Composição } & \multicolumn{1}{c|}{ Classificação } \\
\hline Geração de emprego formal & Alto desenvolvimento (IFDM $>0.8)$ \\
\hline Absorção de mão de obra local & Desenvolvimento moderado $(0.8>$ IFDM $<0.6)$ \\
\hline Salário médio dos empregados & Desenvolvimento regular $(0.6>$ IFDM $<0.4)$ \\
\hline Desigualdade de renda (Gini) & Baixo desenvolvimento (IFDM $<0.4)$ \\
\hline
\end{tabular}

Fonte: Oliveira; Piffer (2017b). Adaptado pelos autores.

Constatou-se que o IFDM Emprego \& Renda extrapola a noção de que o crescimento produtivo determina o nível de desenvolvimento regional ao utilizar parâmetros que avaliam a capacidade dessas economias em gerar inovações, nas quais incorporam os seus residentes. Outrossim, empregou-se informações exclusivamente fornecidas pelos órgãos públicos federais. Nesse caso, a principal fonte é o Relatório Anual de Informações Sociais (RAIS), que divulga dados sobre geração de ocupações e o salário médio pago aos contratados formalmente.

Analisa-se a relação entre o acúmulo de conhecimentos econômicos e alterações nas dinâmicas espaciais tendo como base o conceito de hierarquização espacial. No Brasil, o topo dessa escala está sob a liderança de Brasília, poder exercido através da administração pública, e de São Paulo, o principal centro financeiro do País. As mudanças que acontecem nessas localidades influenciam a sede das Regiões Geográficas Intermediárias, e por causa da aproximação, o restante do seu espaço. Em seguida, como uma onda, as perturbações atingem as Regiões Geográficas Imediatas (Figura 7).

Figura 7 - Hierarquização espacial simplificada no Brasil

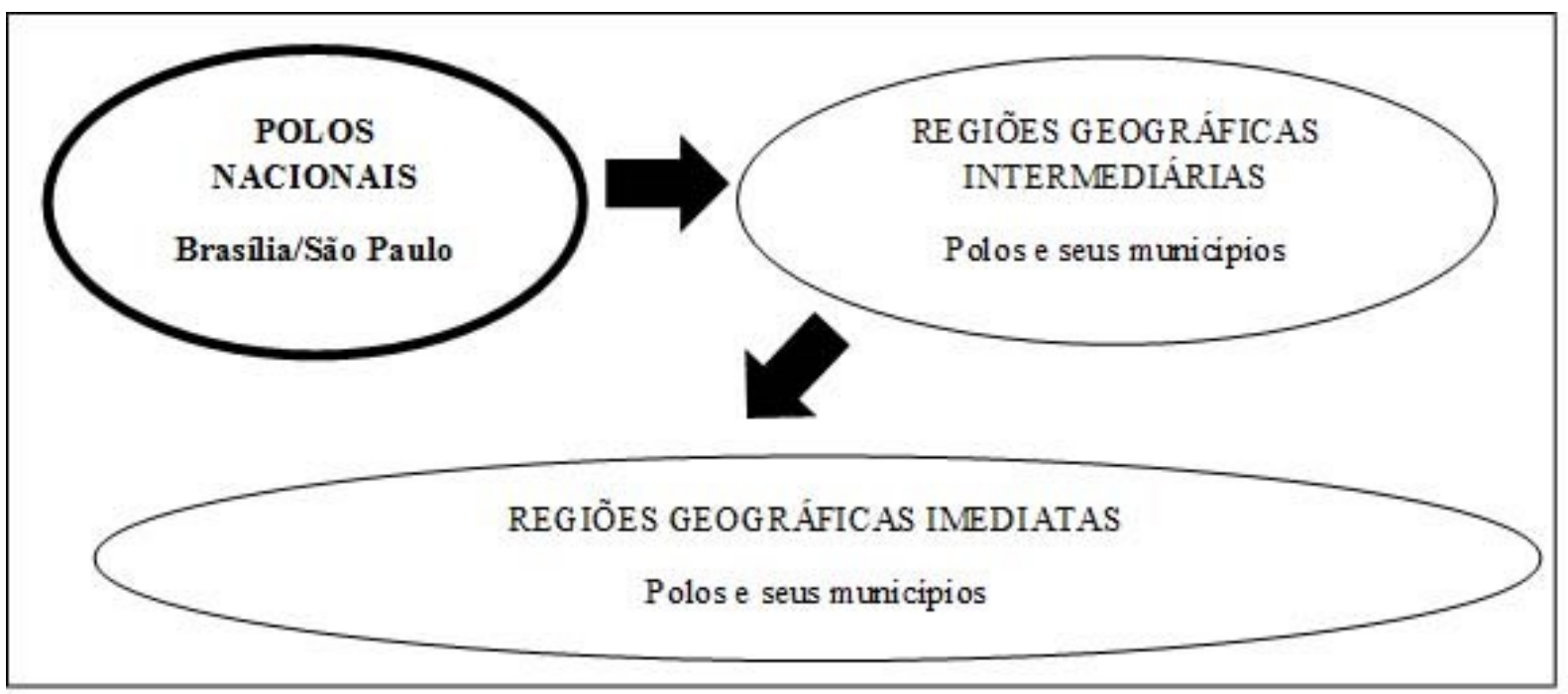

Fonte: Brasil (2008). Adaptado pelos autores.

Seguindo a Figura 7, notou-se a existência de uma relação causa-efeito, isto é, o que acontece em Brasília ou São Paulo reflete-se nas Regiões Geográficas Intermediárias, no caso desta pesquisa, Araguaína, Palmas e Gurupi, e subsequentemente, nas Regiões Geográficas Imediatas. Por exemplo, uma crise originada em decorrência de um colapso no sistema financeiro mundial (2008) ou através de choques internos (2013), em algum momento comprometerá o desempenho das economias regionais brasileiras. Desse modo, a primeira

DRd - Desenvolvimento Regional em debate (ISSNe 2237-9029) 
atingiu diretamente a grande metrópole paulista, e a segunda teve como centro irradiador a capital federal.

Para mensurar a propagação das instabilidades, utilizou-se da Análise Exploratória de Dados Espaciais (AEDE). O seu objetivo consiste em detectar o nível de interação entre duas áreas com alto grau de significância. Por meio disto, comparou-se a taxa de crescimento de 2012 ( ano base $=2010)$ e 2015 (ano base $=2013$ ) da relação entre IFDM Emprego \& Renda e quantidade de postos de trabalhos nas Regiões Econômicas tocantinenses.

Dentre os indicadores espaciais disponíveis, tem-se o I de Moran Global, amplamente utilizado para apontar se em uma dada região, onde apresenta valores elevados ou baixos para uma variável qualquer, o seu entorno também apresenta valores elevados ou baixos, o que caracterizaria uma espécie de cluster no espaço analisado (ANSELIN, 1995).

$$
I^{Z 1 Z 2}=\frac{Z_{1}^{\prime} W Z_{2}}{Z^{\prime}{ }_{1} Z_{1}}
$$

Onde,

$Z_{1}=$ taxa de crescimento do IFDM Emprego e Renda na Região Econômica;

$Z_{2}=$ taxa de crescimento da quantidade de empregos na Região Econômica;

$\mathrm{W}=$ matriz de peso espacial (queen; 1 = se compartilham fronteira; $0=$ se não);

$Z_{1}^{\prime}=$ média da taxa de crescimento do IFDM Emprego e Renda nas localidades que compartilham fronteira.

Admitindo que o I de Moran Global equivale a um coeficiente de regressão linear, elaborou-se um gráfico para visualizar a relação entre o valor do atributo de cada elemento padronizado $-Z_{1}$ - com a média dos valores dos atributos dos seus vizinhos $-W Z_{2}$, seguindo esta classificação:

- primeiro quadrante (I) apresenta taxas de crescimento acima da média com vizinhos também com desempenhos neste sentido (Alto-alto);

-quadrante três (III) contém os pares, unidade e vizinhos, com taxas de crescimento abaixo da média (Alto-baixo);

-quadrante dois (II) detém as regiões e respectivos vizinhos com desempenhos abaixo e acima da média (Baixo-alto);

- quadrante quatro (IV) contém as regiões e vizinhos, respectivamente, com taxas de crescimento acima e abaixo da média (Baixo-baixo).

Erikson; Hane-Weijman (2015) e Pontarolo; Serpieri (2018) aperfeiçoaram a análise denominando os quadrantes. Nesse sentido, adotou-se as seguintes nomenclaturas:

-Vencedores (Alto-alto): regiões que cresceram a sua produção mesmo em uma conjuntura instável;

-Turbulentos (Baixo-alto): regiões que experimentaram um período de pré-crise; 
-Estáveis (Alto-baixo): regiões que permaneceram com desempenho mediano;

-Marginalizadas (Baixo-baixo): regiões fortemente afetadas pelas crises.

Aumentou-se a precisão da análise espacial empregando o I de Moran Local ou LISA, indicador que permite a visualização de clusters com alto nível de significância.

$$
I_{i}^{Z 1 Z 2}=Z_{l i} W Z_{21}
$$

Onde,

$Z_{l 1}=$ taxa de crescimento do IFDM Emprego e Renda na Região Econômica;

$Z_{2 i}=$ taxa de crescimento da quantidade de empregos na Região Econômica vizinha;

$\mathrm{W}=$ matriz de peso espacial (queen; $1=$ compartilham fronteira até a segunda ordem; $0=$ se não).

Se os valores de $I_{i}^{Z 1 Z 2}$ forem diferentes de zero, indica que a unidade i está espacialmente associada aos seus vizinhos. Como a distribuição dos Ii é desconhecida, a forma de obtê-la é através de permutações aleatórias dos vizinhos de cada unidade com as demais áreas, até atingir uma pseudo-distribuição para a qual possa computar os parâmetros de significância. A comparação dessas com a observada permite inferir se a correlação espacial é significativa se estiver superior a 95\% (ANSELIN, 1995).

Neste procedimento, modificou-se a matriz de peso W em relação ao I de Moran Global. Como as delimitações geográficas em análise possuem grandes dimensões, tornou-se necessário aumentar os seus raios de atuação para que o LISA detecte interações espaciais com alto nível de significância. Por isso, adotou-se o critério "vizinho dos seus vizinhos" ou vizinhança de segunda ordem.

Em seguida, constroem-se mapas coropléticos chamados de Moran Map, que mostram os municípios com baixo ou alto nível de desempenho econômico. Além disso, as ilustrações expõem se essas características estão em modo de compartilhamento ou encontram-se isoladas. Por fim, elaborou-se uma nova ilustração geográfica com o fito de sintetizar os resultados obtidos.

\section{RESULTADOS E DISCUSSÕES}

No período de 2010/2012, o indicador de associação espacial global detectou que a maioria das Regiões Econômicas do TO se encontrava marginalizada. Nesse rol incluem-se Miracema, Gurupi, Palmas, Porto Nacional, Paraíso e Guaraí, localizadas no centro e sudoeste do estado, que obtiveram retração em suas atividades durante os anos de crise mundial. Em compensação, Araguatins, no extremo norte, mostrou resistência nesse ínterim, tornando-se a única que cresceu a sua capacidade de gerar inovações produtivas.

Por sua vez, Araguaína, a segunda maior economia regional do estado, atravessou um período de turbulência. Todavia, é considerada como um caso exemplar, pois a sua região se

DRd - Desenvolvimento Regional em debate (ISSNe 2237-9029) 
compõe de 21 municípios, sendo a maioria de pequeno porte. Apesar dessa limitação, a crise afetou-a moderadamente em relação com Palmas, Paraíso, Porto Nacional e Gurupi, importantes áreas produtivas do estado (Figura 8).

Figura 8 - Relação entre a taxa de crescimento do IFDM Emprego \& Renda (2012, ano base $=2010)$ e a variação no emprego ( $I$ de Moran = -0.10) nas Regiões Econômicas do Tocantins.

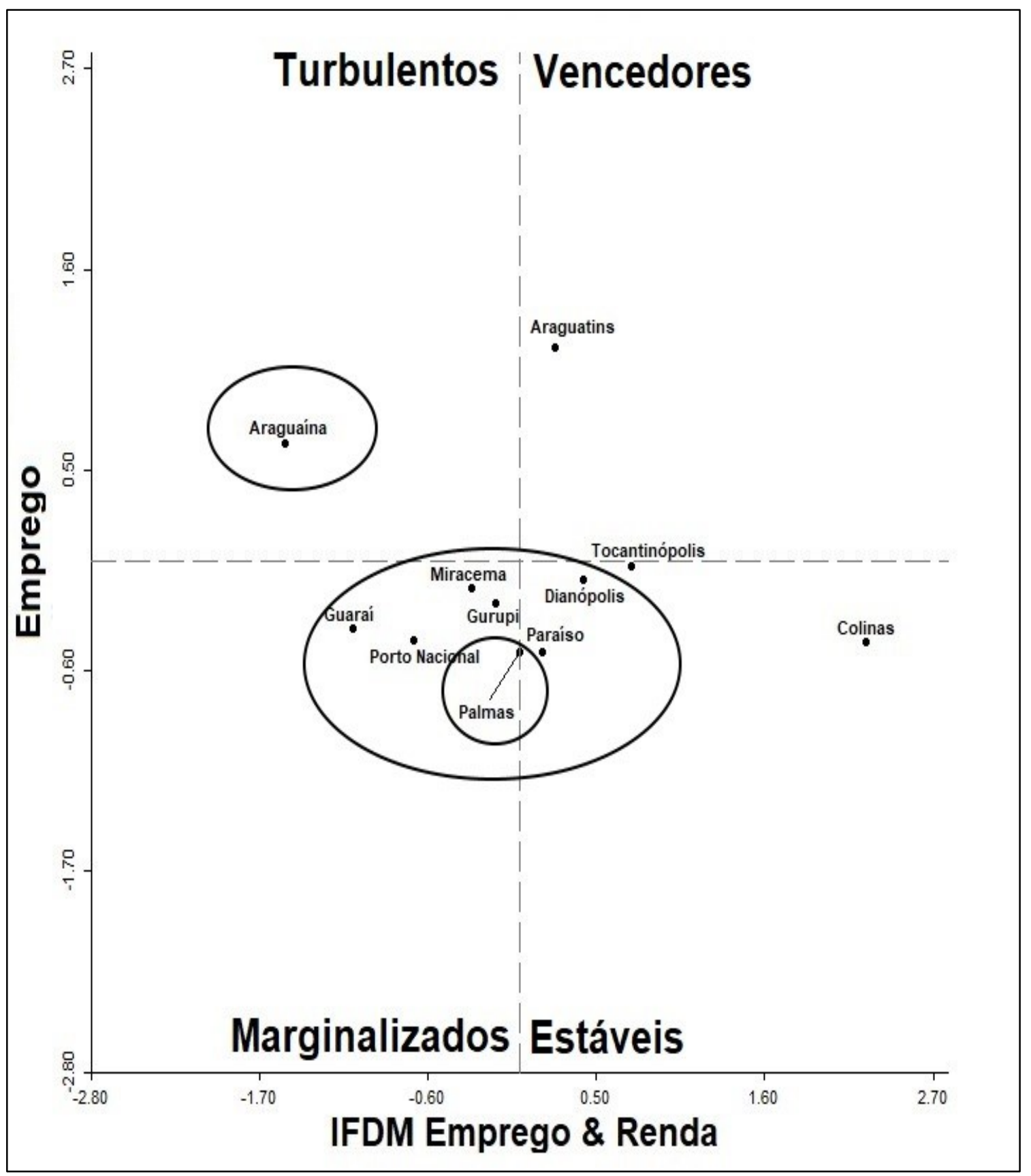

Fonte: Resultados da pesquisa.

Palmas está no centro de uma área onde os seus vizinhos possuem desempenho econômico similar (Figura 8). Destacou-se Guaraí, que embora pertença à Região Geográfica Intermediária de Araguaína, associou-se com a capital. Por sua vez, na faixa norte do estado, as economias regionais que participam desse contexto encontram-se distante umas das outras, demonstrando, assim, descompasso entre o polo estadual e a sua periferia. 
Na visualização do Cluster Map, tornou-se nítido a inexistência de correlação na faixa setentrional do Tocantins. Em compensação, contatou-se uma aglomeração de Regiões Econômicas com desempenho irregular localizada ao norte de Palmas (Figura 9).

Figura 9 - Cluster Map do IFDM Emprego \& Renda (2012, ano base =2010) e a variação no emprego nas Regiões Econômicas do Tocantins.

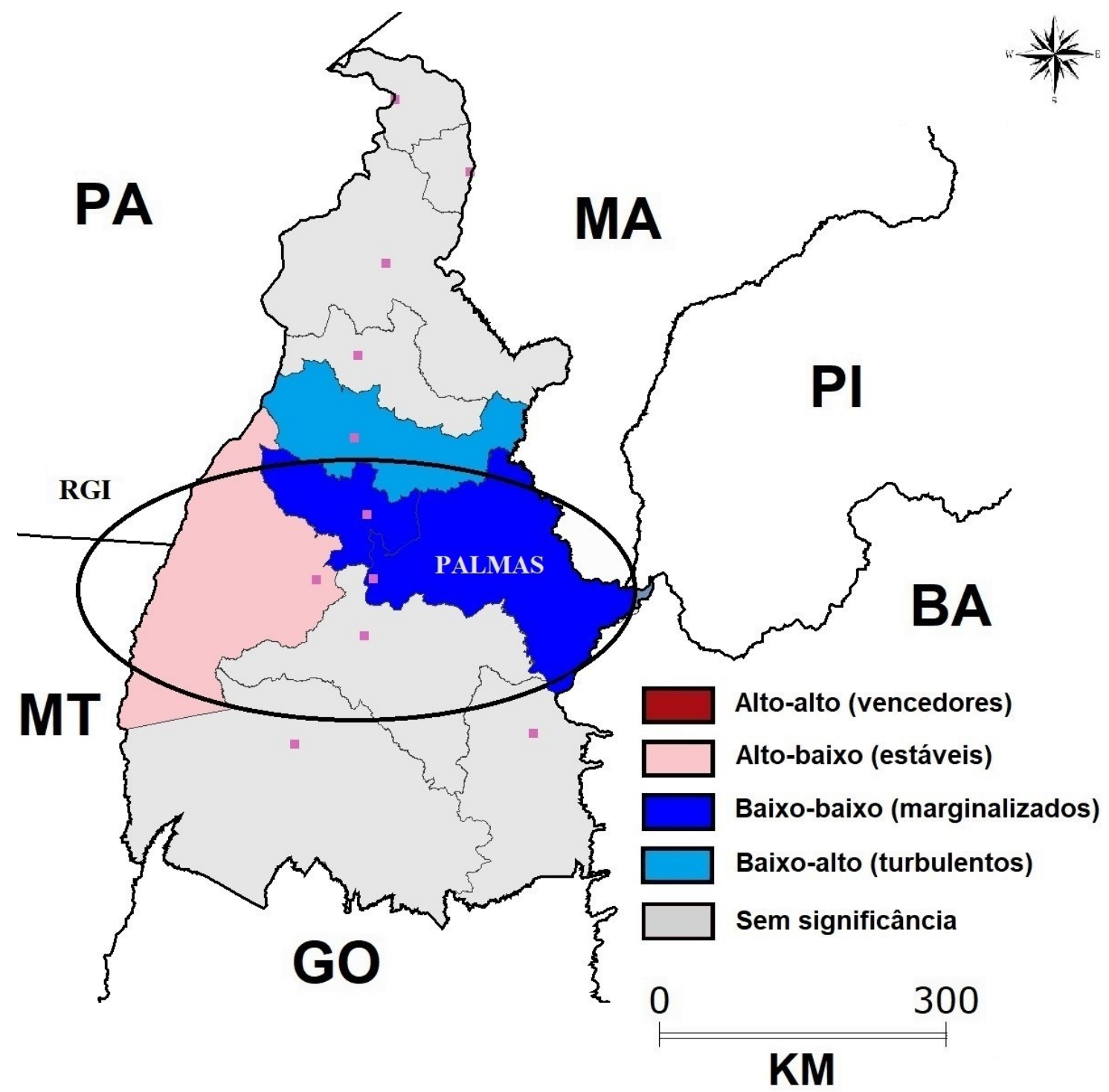

Fonte: Resultados da pesquisa.

Há uma estreita relação de dependência entre Palmas, Miracema e Guaraí, enquanto que Paraíso obteve desempenho estável mesmo com as perturbações ocorridas nos seus vizinhos. Esperava-se que o raio de influência da capital fosse maior em vista do que se constatou na Figura 8. Todavia, em termos de significância estatística, o LISA demonstrou que a região da capital possui uma polarização restrita.

Entre 2013 e 2015, tem-se um cenário diferente do período anterior. Nenhuma Região Econômica tocantinense obteve alto desempenho produtivo, dado que Araguatins adentrou em 
uma fase turbulenta. Na outra via, Paraíso, Palmas, Miracema, Gurupi e Guaraí estabilizaram a sua produção, recuperando-se de um dos períodos mais tensos da história brasileira. No entanto, Porto Nacional continuou marginalizado, assim como Colinas e Dianópolis, que se sucumbiram aos choques internos (Figura 10).

Figura 10 - Relação entre a taxa de crescimento do IFDM Emprego \& Renda $(2015$, ano base $=2013)$ e na variação no emprego ( $I$ de Moran = -0.18) nas Regiões Econômicas do Tocantins.

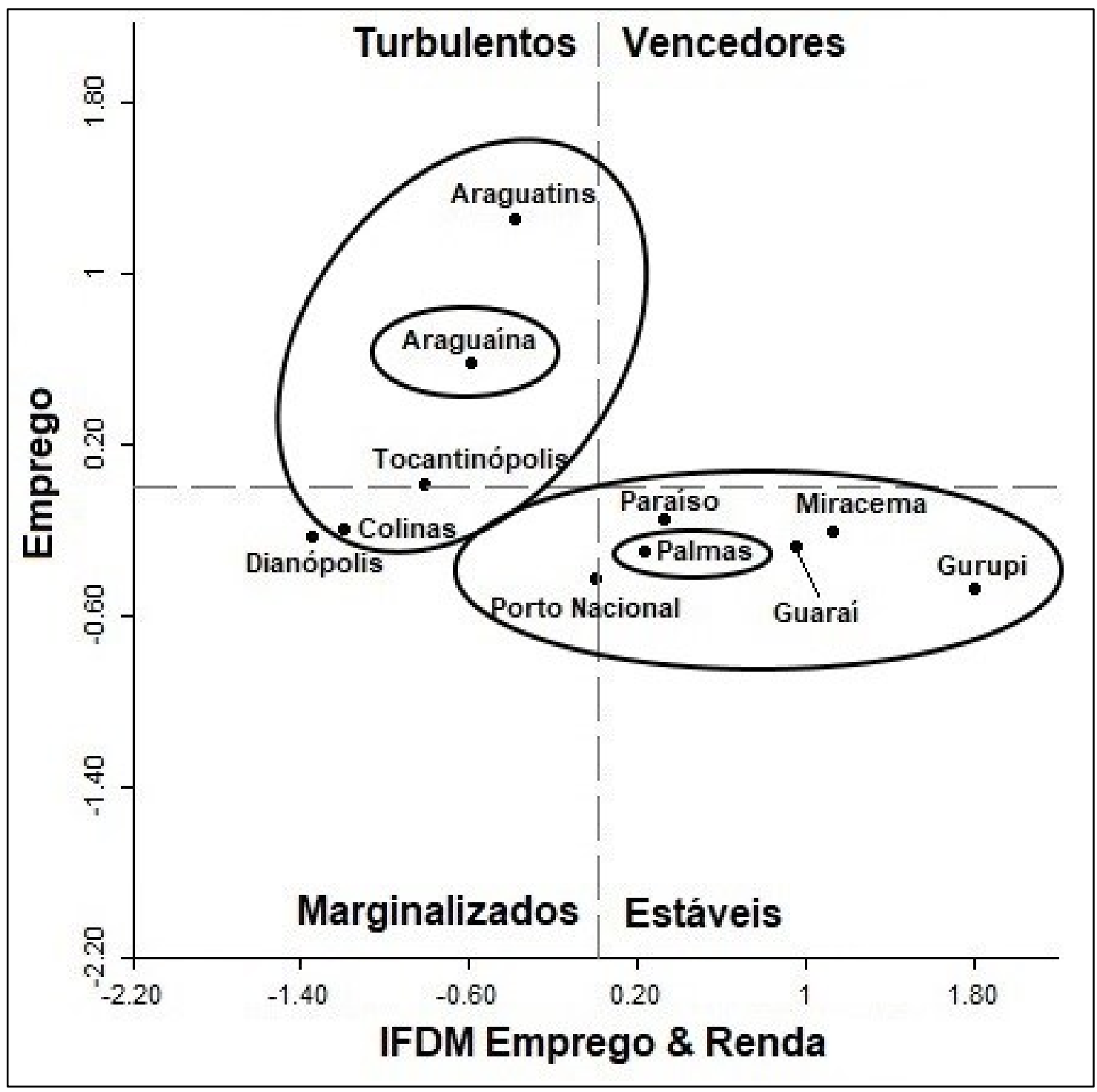

Fonte: Resultados da pesquisa.

Em uma análise ampla, o norte do estado, formado por Araguatins, Tocantinópolis e Colinas, sentiu os efeitos da recessão iniciada em 2013, tanto que o seu desempenho acompanhou o de Araguaína, a região de referência. Enquanto isso, a faixa central e sul do Tocantins, com ressalva para Dianópolis e Porto Nacional, direcionaram-se para um crescimento produtivo pós-crise. Nesse sentido, constatou-se uma diferenciação espacial no que concerne à capacidade das economias regionais em resistir às variações no cenário político e internacional.

No que tange ao I de Moran Local, Paraíso persistiu no padrão de 2010/2012, sendo acompanhado por Palmas e Miracema, que anteriormente passaram por um período de 
turbulência. Sobre as demais Regiões Econômicas do centro e sul do estado, incorreu o surgimento de clusters com alto nível de significância (Figura 11).

Figura 11 - Cluster Map do IFDM Emprego \& Renda (2012, ano base = 2010) e a variação no emprego nas Regiões Econômicas do Tocantins.

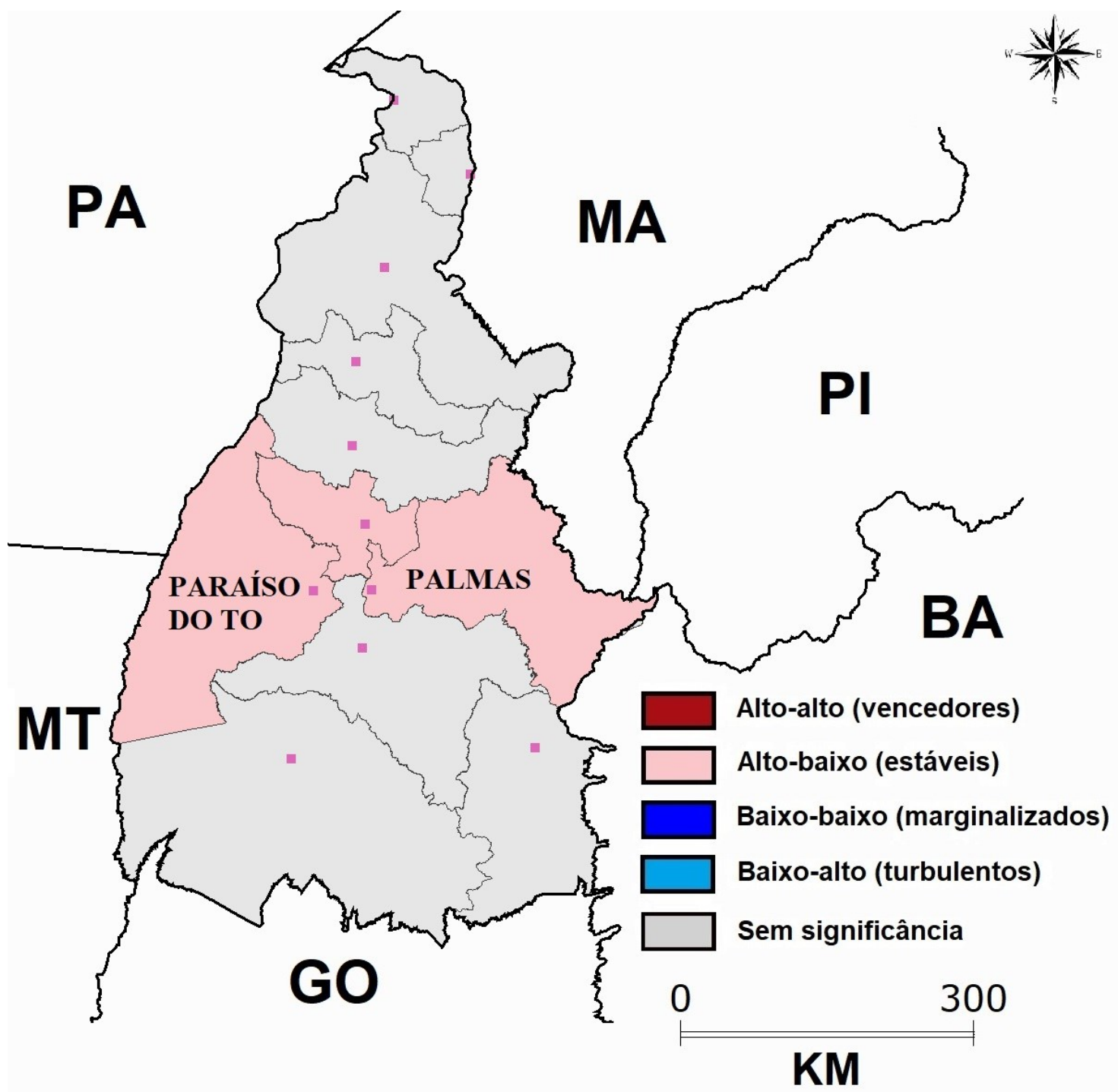

Fonte: Resultados da pesquisa.

Novamente, no norte do estado constatou-se nenhum aglomerado, demonstrando que as suas regiões possuem restrita capacidade de interagir espacialmente. Apesar disso, com base nos resultados do I de Moran Global, inferiu-se que as economias periféricas tocantinenses estão sob a influência de Araguaína e Palmas. Em compensação, de acordo com os resultados gerais da pesquisa, inexiste uma relação espacial significativa entre Gurupi e Dianópolis. $\mathrm{O}$ primeiro nitidamente associou-se com a capital do TO, enquanto que o segundo, localizado no sudeste do estado, subordinou-se a uma outra dinâmica, provavelmente com a do oeste baiano, liderado por Barreiras e Luís Eduardo Magalhães ${ }^{3}$, e do extremo nordeste goiano, sob a tutela de Campos Belos e Posse (Figura 12).

${ }^{3}$ Afirmação fundamentada na pesquisa: Oliveira e Araújo (2012). 
Figura 12 - Área de interação direta exercida por Araguaína e Palmas no estado do Tocantins.

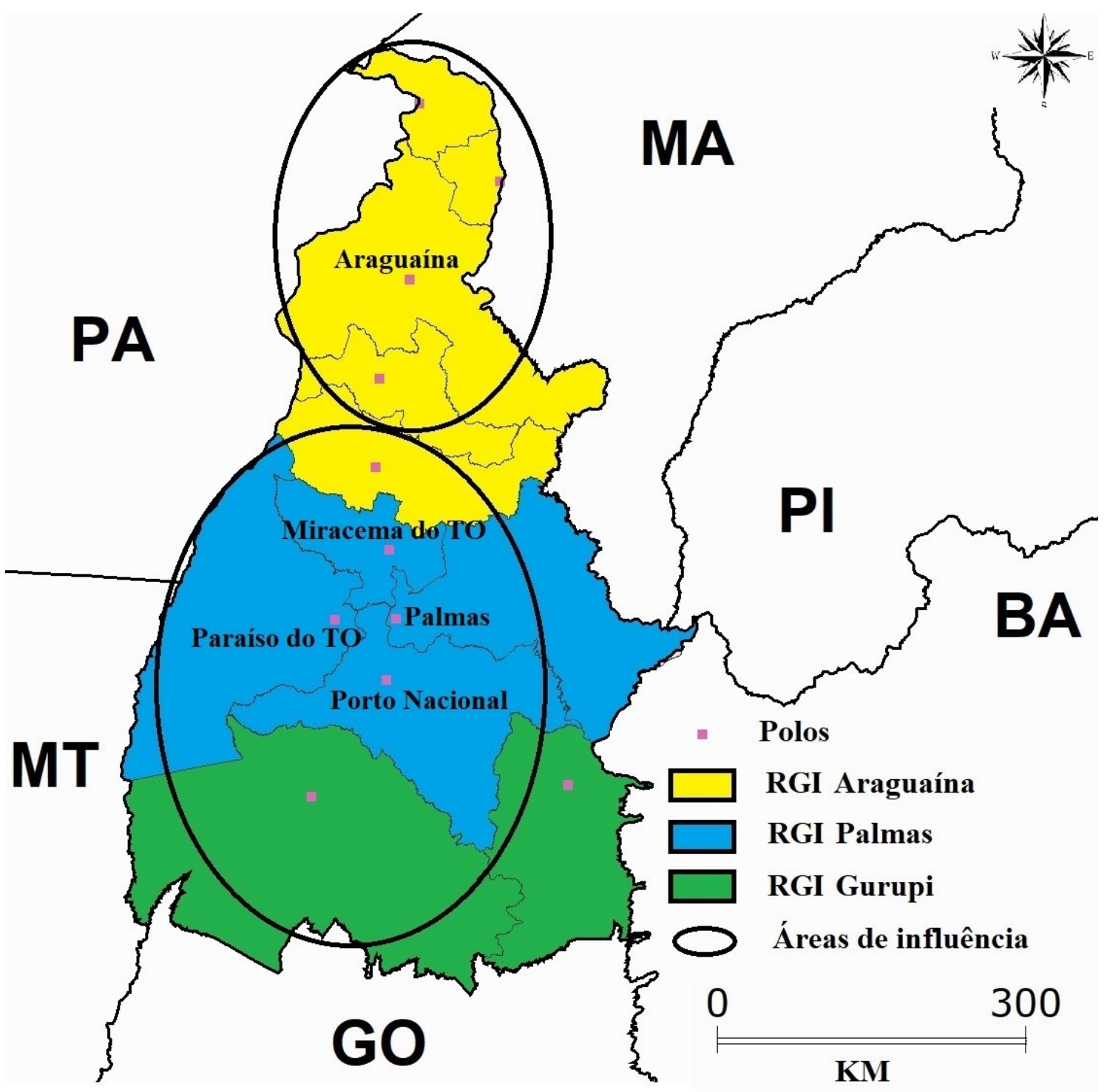

Fonte: Resultados da pesquisa.

Na zona de influência de Araguaína (Figura 12), as economias regionais, com destaque para Araguatins, resistiram à primeira crise. Todavia, na segunda, atravessaram um período turbulento similar ao da região-polo entre 2010 e 2012. Enfatiza-se que Guaraí, embora faça parte dessa RGI, relacionou-se com Palmas. Desse modo, insere-se na área de influência da capital. Sobre a RGI de Gurupi, tratou-se de uma área que despossui uma dinâmica própria, inserindo-se, portanto, na esfera da capital estadual. Essa situação relaciona-se com a sua limitada capacidade de aprisionar conhecimentos produtivos, dificultando a consolidação de uma rede de integração espacial no sudoeste tocantinense.

\section{CONCLUSÃO}

A pesquisa analisou o desempenho das Regiões Econômicas do Tocantins durante os anos de crise recente. As informações iniciais mostraram que houve diminuição da sua produção agregada e dos repasses oriundos da União entre 2010/2015, período caracterizado

DRd - Desenvolvimento Regional em debate (ISSNe 2237-9029) 
pelas instabilidades no cenário político e econômico. Consequentemente, tendo como suporte o referencial teórico e os resultados dos indicadores I de Moran global e local (LISA), esses distúrbios afetaram as relações espaciais presentes nessa Unidade da Federação.

Na primeira fase da crise, aquelas regiões localizadas no norte do estado, Araguaína, Araguatins, Tocantinópolis e Colinas, seguiram dinâmicas próprias, cada uma com desempenho particular, enquanto que Palmas obteve característica similar a dos seus vizinhos. O LISA confirmou que a capital se associou com Miracema e Guaraí, sendo que esse pertence à RGI de Araguaína. Por outra via, em 2013/2015, tem-se um cenário onde as áreas periféricas acompanham o desempenho dos polos, embora o I de Moran local apontou somente um aglomerado, formado precisamente no centro do Tocantins. Ademais, nenhuma atingiu o patamar "vencedor" nesse intervalo, demonstrando a gravidade dessa crise advinda de Brasília. Finalmente, inexiste evidências que demonstrem a presença de interações espaciais na Região Geográfica Intermediária de Gurupi.

A escassez de associações com alto nível de significância ampara-se na insuficiência de conhecimentos produtivos acumulados nas Regiões Econômicas do TO. Ressaltou-se que essas integraram-se no contexto econômico vigente a poucas décadas, por isso, o processo de acumulação de capital está em fase inicial. Com exceção de Paraíso, que auferiu um desempenho regular entre 2010 e 2015, o restante, em algum momento no período de análise, experimentou os efeitos negativos das crises. Ademais, obras importantes na área da infraestrutura como a operação do trecho da Ferrovia Norte-Sul entre Porto Nacional e Anápolis-GO, assim como a construção da Ferrovia de Integração Oeste-Leste, no sul e sudeste do estado, e o porto fluvial de Praia Norte, no extremo norte, que dinamizariam as produções regionais, encontram-se em estado de letargia.

Diante dos obstáculos citados, denotou-se que Palmas e o seu entorno superaram os efeitos negativos da crise por causa da proximidade das suas centralidades urbanas. Isso ocorreu mediante ao adensamento de comércio e serviços especializados ao longo do tempo, essencialmente em Porto Nacional, Paraíso e Miracema, e também devido à disponibilidade de infraestruturas como o aeroporto que oferta voos regulares na capital, o terminal ferroviário de cargas no distrito de Luzimangues, e as rodovias federais e estaduais pavimentadas que as conectam com Brasília e Goiânia. Sem esses dispositivos, as economias regionais continuariam marginalizadas, situação que aconteceu no norte do estado, cuja Araguaína, o principal articulador nessa parte do Tocantins, foi incapaz de mover-se da condição de turbulento, fazendo com que as demais acompanhassem o seu compasso.

Em virtude disto, afirmou-se que, além de provocar o desemprego e aumentar o nível de pobreza, as instabilidades prejudicaram a expansão das áreas periféricas, o fortalecimento das centralidades urbanas no Tocantins e o surgimento de futuras outras Regiões Econômicas. Em suma, as perturbações retraíram as funcionalidades dos seus núcleos urbanos, comprometendo, desse modo, o processo de fortalecimento das redes estaduais.

Por fim, ressalta-se a importância de consolidar um projeto de desenvolvimento nacional em prol da inovação e da sustentabilidade. Contudo, em momentos de crises agudas, os governantes brasileiros recorrem à iniciativa privada na tentativa de solucionar as falhas de mercado. Trata-se de um equívoco, uma vez que a história demonstrou que as ações conjuntas entre empresas, Estado e sociedade civil é o principal modo de recuperar as economias periféricas e promover o crescimento por longos períodos. Sendo assim, para os próximos 
estudos recomenda-se a análise do desempenho das aglomerações urbanas durante o período de crise. A partir disso, busca-se a constatação de que essas áreas, ao concentrar conhecimentos produtivos, têm vantagens para amenizar os problemas advindos das crises do que as demais regiões.

\section{REFERÊNCIAS}

ANSELIN, L. Local indicator of spatial association - LISA. Geographical Analysis, v. 27, n. 2, $\mathrm{p}, 93-115,1995$.

BECKER, B. K. Dinâmica urbana na Amazônia. In: DINIZ, C. C.; LEMOS, M. B. (org.). Economia e território. Belo Horizonte: UFMG, 2005, p. 401-428.

BISHOP, P. Knowledge diversity and entrepreneurship following an economic crisis: an empirical study of regional resilience in Great Britain. Entrepreneurship \& Regional Development, v. 31, n. 5-6, p. 1-20, 2018.

BRASIL. Ministério do Planejamento, Orçamento e Gestão. Estudo da dimensão territorial para o planejamento: volume III: regiões de referência. Brasília, DF, 2008.

Divisão regional do Brasil em regiões geográficas imediatas e regiões geográficas intermediárias. Rio de Janeiro: IBGE, 2017.

Dados macroeconômicos. Disponível em: $<$ http://www.ipeadata.gov.br/>. Acesso em: 21 out. 2018

ERIKSSON, R.; HANE-WEIJMAN, E. How do regional economies respond to crises? The geography of job creation and destruction in Sweden (1990-2010). European Urban and Regional Studies, v. 24, n. 1, p. 1-17, 2015.

ESPINAL, A. E. Recesiones regionales en México: diversidad y causas. Análisis Económico, v. 60 , p. $81-113,2010$.

FLORES, K. M. Caminhos que andam: o rio Tocantins e a navegação fluvial nos sertões do Brasil. Goiânia: Ed. UCG, 2009.

GILPIN, R. O desafio do capitalismo global: a economia mundial no século XXI. Rio de Janeiro: Record, 2000.

HERSEN, A; LIMA, J. F. O efeito transbordamento da crise econômica internacional. Texto de Economia, v. 13, n. 1, p. 25-45, 2010.

HIRSCHMAN, A. O. Transmissão inter-regional e internacional do crescimento econômico. In: SCHWARTZMAN, J. (Org.). Teoria regional e urbana: textos escolhidos. Belo Horizonte: UFMG, 1977, p. 35-52.

ÍNDICE FIRJAN DE DESENVOLVIMENTO HUMANO (IFDM). Downloads. Disponível em: <http://www.firjan.com.br/ifdm/>. Acesso em: 21 out. 2018. 
NORTH, D. C. Teoria da localização e crescimento econômico regional. In SCHWARTZMANN, J. (Org.). Teoria regional e urbana: textos escolhidos. Belo Horizonte: UFMG, 1977, p. 291-313.

OLIVEIRA, T. J. A; ARAÚJO, A. F. V. Interações produtivas agropecuárias no Estado do Tocantins: uma análise espacial. Amazônia: Ciência \& Desenvolvimento, v. 8, n. 15, p. 161$178,2012$.

OLIVEIRA T. J. A.; PIFFER, M. Palmas: lugar central ou enclave no centro-norte do Brasil? Novos Cadernos NAEA, Belém, v. 18, n. 2, p. 199-216, set./2015. Doi: http://dx.doi.org/10.5801/ncn.v18i2.2000.

. Da Amazônia Legal ao Centro Norte: as transformações econômicas espaciais. RBEUR, v. 19, n. 1, p. 164-178, 2017a. Doi: https://doi.org/10.22296/2317$1529.2017 \mathrm{v} 19 \mathrm{n} 1 \mathrm{p} 164$.

O desenvolvimento regional do Centro Norte brasileiro: uma abordagem a partir da teoria de Douglass North. Revista Política e Planejamento Regional, v. 4, n. 2, p. 211-228, $2017 b$.

; RODRIGUES, W. Incentivos fiscais e as variações locacionais dos ramos agroalimentares no Tocantins. Economia \& Região, v. 6, n. 1, p. 129-145, jan./jun. 2018. Doi: $10.5433 / 2317-627 X .2018 v 6 n 1 p 129$.

PAULA, L. F.; PIRES, M. Crise e perspectivas para a economia brasileira. Estudos Avançados, v. 31, n. 89, p. 125-144, mar. 2017. Doi: 10.1590/s0103-40142017.31890013.

PERROUX, F. O conceito de polo de crescimento. In SCHWARTZMANN, J. (Org.). Teoria regional e urbana: textos escolhidos. Belo Horizonte: UFMG, 1977. p. 99-110.

PONTAROLO, N.; SERPIERI, C. A composite policy tool to measure territorial resilience capacity. Luxemburgo: European Union, 2018. Doi: 10.2760/40371.

PRADO JÚNIOR, C. História econômica do Brasil. São Paulo: Editora Brasiliense, 2012.

SALLES, G. V. Economia e escravidão na Capitania de Goiás. Goiânia: UFG, 1992.

SOUZA, J. A elite do atraso: da escravidão à lava jato. Rio de Janeiro: Leyia, 2017. , J. G.; SPINOLA, N. D. Medidas do desenvolvimento econômico. Revista de Desenvolvimento Econômico -RDE-, v. 1, n. 36, p. 78-113, 2017.

TESOURO NACIONAL. Dados consolidados. Disponível: de $<$ https://www.tesouro.fazenda.gov.br/web/stn/-/transferencias-constitucionais-e legais\#Dados_consolidados $>$. Acesso em: 21 out. 2018.

Artigo recebido em: 21/06/2019

Artigo aprovado em: 17/08/2019

Artigo publicado em: 28/08/2019 